\title{
Impact of Physical Activity on Alzheimer's Disease: A Randomised Controlled Study
}

\author{
Toulotte Claire ${ }^{1,2, *}$, Caby Isabelle ${ }^{2,3, \#}$, Olivier Hélène ${ }^{2, \#}$ and Olivier Nicolas ${ }^{3, \#}$ \\ ${ }^{1}$ Université de Valenciennes, Faculté des Sciences et Métiers du Sport, Le Mont Houy, F-59313, \\ Valenciennes Cedex 09, France; LAMIH, CNRS, UMR CNRS 8201, F-59313, Valenciennes Cedex 09, \\ France \\ ${ }^{2}$ University of Artois, Faculté des sciences du sport et de l'éducation physique, Chemin du Marquage, \\ F-62800, Liévin, France \\ ${ }^{3}$ University of Lille Nord de France, F-59000, Lille, France; URePSSS, EA 4488, F-59790, Ronchin, France
}

\begin{abstract}
Purpose: To study the effects of physical training on behavior and balance issues in elderly people afflicted with Alzheimer's disease.

Method: Forty patients (average age: 80 years old) participated in the study. The individuals were placed into two groups: a control group, which did not participate in any kind of training, and a trained group, which followed an eightweek training program. The training program comprised 2-3 sessions of light physical activity or walking per week; each session had an average duration of 15-55 min. Before (T1) and after (T2) the training program, an assessment of the psychical, psychological, physical, and functional parameters was conducted.

Results: Upon completion of the physical training program, there was a significant $(p<0.05)$ improvement in the Tinetti test (T1: $19.5 \pm 4.2 \mathrm{~s}$; T2: $20.1 \pm 4.1 \mathrm{~s}$ ), a significant decrease in the completion time of the "get up and go" track for all of the participants (T1:23.1 $\pm 8.1 \mathrm{~s}$; T2: $19.5 \pm 6.1 \mathrm{~s})$, and a significant reduction in the seriousness of the behavioral issues observed.

Conclusion: This preliminary study revealed that physical training had an overall beneficial impact on Alzheimer's patients, especially on their behavior and balance.
\end{abstract}

Keywords: Elderly people, physical activity, behavior, balance.

\section{INTRODUCTION}

The rehabilitation and care of patients afflicted with Alzheimer's disease is a major public health challenge. In 2006, it was estimated that 26.6 million people worldwide are affected by this disease [1]. By 2050, it is estimated that 106.8 million people will have Alzheimer's disease, a ratio of 1 to 85 . This disease causes problems with memory (in particular, recent memory), temporary spatial disorientation, apraxia, issues with language, and anosognosia. Changes in behavior and humor are present throughout the disease progression. A study by Ownby et al. [2] revealed that depression affects a large number of Alzheimer's patients: as the disease progresses, the number of issues with communication increases. Behavioral problems are frequent; indeed, agitated behaviors are $2 \times$ more prevalent in patients with Alzheimer's disease. The appearance of behavioral issues worsens the prognosis and correlates with the evolution towards dementia [3-5]. According to Beauchet et al. [6], 25\% of people with this disease

\footnotetext{
*Address correspondence to this author at the Université d'Artois, Faculté des Sciences du Sport, Chemin du Marquage, 62800 Lievin, France; Tel: (33) 32145-85-00; Fax: (33) 321-45-85-01, E-mail: ctoulotte@wanadoo.fr

\#Co-Authors E-mail: isabelle.caby@univ-artois.fr, h.olivier2@wanadoo.fr: nicolas.olivier@univ-lille2.fr
}

have issues with walking and balance. Since cognitive decline is known to be a cause of falling, people with cognitive decline experience $2 \times$ the risk of falling. Indeed, demented people have a fall risk $8-10 \times$ higher than non-demented people. The limitation of physical activities has been identified as an important indicator in balance [7].

The beneficial effects of physical activity on organisms are generally accepted and are now understood for specific subsets of the population. The regular practice of physical activity can delay or slow down some deleterious processes linked to ageing or to a specific pathology [8]. Physical activity seems to affect these processes through three different mechanisms: it preserves physical [9-11], psychological [12,13], and social health [14], enabling a person to preserve their independence and integration in a group. Indeed, functional independence is the basis for balance, health, and quality of life [15]. Establishing physical exercises for Alzheimer's patients has salutary effects on both their physical and psychological functions and could be a way to improve their cognitive and behavioral processes. Therefore, it could increase their quality of life [16-19]. 
Beauchet et al. [6] demonstrated the benefit of regular physical activity (e.g., walking, cycling, gardening, swimming) for individuals with or at risk of Alzheimer's disease. This benefit is twofold: physical activity decreases the risk of dementia in healthy individuals and reduces behavioral and locomotive problems in demented patients. Therefore, physical activity can play a protective role. A daily practice of at least 30 minutes of physical activity can reduce psycho-behavioral issues and influence mood by reducing negative thoughts and increasing positive ones [12].

Regardless of the pathology, physical exercise seems to play a determining role in therapeutic care. However, the beneficial effects of physical activity for patients with Alzheimer's disease are not yet well known. The objective of this preliminary study was to analyze the effects of physical training for these patients using individual and group physical activities. We hypothesized that this type of exercise program would have a positive impact on their behavior, depressive state, and balance.

\section{MATERIALS AND METHODS}

\subsection{Participants}

The study comprised a population of 40 individuals, with an average age of 80 years old, including residents of two institutions with an Alzheimer division located in France in the Pas-de-Calais department. Before the beginning of this study, the purpose was explained to the volunteers and the families. Forty volunteers participated in this study, which was reviewed and approved by the local University Ethics Committee. Before experimentation and after being informed of the entire protocol, each patient and each family signed a written consent form. A summary of the patients' anthropometric, psychological, and physical characteristics is available in Table $\mathbf{1}$.

The inclusion criteria were elderly patients who: had Alzheimer's or a similar disease, could understand instructions and agree to participate in physical activities, and were not bedridden, or have moving disabilities that would preclude physical activity.

The psychological state of the patients was evaluated every year with a Mini Mental State examination (MMS) [20].

Then, the 40 subjects were randomly divided into 2 groups of 20 subjects. We placed the participants into two groups: an experimental group with 20 patients who followed an eight-week training program and a control group with 20 patients who did not participate in any physical activity during this period. The evaluation was made after an eight-week training program in order to assess if the training load was sufficient.

\subsection{Experimental Protocol}

The participants were evaluated two days before the start of the training program and two days after it by the same evaluator. The evaluations consisted of balance tests, behavioral tests, and a test for depression.

\subsection{Measured Parameters}

\subsubsection{Tinetti Test [21]}

The Tinetti test precisely identifies walking and balance deficiencies in elderly people during different daily life situations. The test is divided into two parts and is evaluated with 28 points. The first part evaluates balance and is scored on 16 points. Balance during sitting, standing, and in a closed eyes position are observed during this portion. The second part of the test is dedicated to walking and is evaluated on 12 points. Straight walking is performed and different parameters are evaluated: the length, height, symmetry, and continuity of the steps.

\subsubsection{Get Up and Go Test [22]}

This test evaluates various parameters such as the sitting/standing transfer, walk, and direction changes. The test methodology is the following: participants started by sitting on a chair with armrests, they had to get up and walk 3 meters towards a wall, turn around without touching the wall, and come back to sit on the chair. The test was timed; the timer started as soon as the person tried to get up from the chair and stopped when they returned to a seated position.

\subsubsection{Neuropsychiatric Inventory [23] (NPI)}

This test provides information about the existence, seriousness, and consequences of any behavioral issues. It assesses 12 types of behaviors (delirious ideas, hallucinations, agitation, depression, anxiety, mood elation, apathy, disinhibition, irritability, abusive moving behavior, appetite issues, and sleeping difficulties). If a participant presented one of these behaviors, the seriousness of the behavioral issue and consequences, i.e., the extent that this behavior was demanding for the person, was evaluated. The seriousness is evaluated on 36 points and is 
designated as "light, medium, or strong". The impact is graded on 60 points and is scored as "none, minimal, slightly, moderately, serious, or very serious". This test was evaluated by a person from the institute who knew the patients well.

\subsubsection{The Mini-GDS (Geriatric Depression Scale) [24]}

For the participants who exhibited depressive behavior (indicated by the results of the NPI test), we employed the mini-GDS. This is a scale for geriatric depression with four questions $\left(1^{\text {st }}\right.$ : do you feel discouraged and sad?, $2^{\text {nd }}$ : do you have the feeling that your life is empty? $3^{\text {rd }}$ : do you feel happy most of the time?, and $4^{\text {th }}$ : do you feel that your life is hopeless?). The participants must situate themselves in the past (approximately one week) and should reply with a yes or no.

\subsection{Training Program}

The training program was based on physical activity and walking to improve the patient's balance and behavior issues.

To correctly perform the physical activity, the population was divided into four groups, which were determined following the Autonomy Gerontology IsoResources Group (AGGIR) matrix. This tool can evaluate the degree of loss of autonomy or the degree of physical and psychological dependence. The first group corresponds to the autonomous residents and comprised four people. The second group consisted of five people and corresponds to the residents who are a bit less autonomous but who still have a lot of capacities. The third group comprised four people who are more dependent and have walking issues. Finally, the last group corresponds to the patients in wheelchairs. It consisted of four people. In addition to these groups, three residents received short, individual sessions because they could not stay focused for long periods of time.

All of the patients followed a program of two sessions of physical activity and one walking session per week for two months. The gymnastic sessions lasted 15-55 minutes, depending on the capacity of the group. The walking sessions generally lasted 5-15 minutes and were performed individually. All of the groups performed the same type of exercise but with different durations and intensities, depending on their capacity. A different theme was proposed for each session: development of muscular strength, flexibility (using objects such as rings, hoops, sticks, balls, or scarves), or static and dynamic balance.
Each session was divided into three parts: a warmup consisting of an articular mobilization of the body; the main part of the session, composed of exercises for muscular strength, flexibility, movement, and games to facilitate competition between the residents without putting them in failure situations; and a cooling down period with stretching, breathing, and relaxation exercises. All of the exercises were proposed by an adapted physical activity teacher.

\subsection{Statistics}

The statistical calculations were carried out with the SigmaStat software. The results are expressed as an average and its standard deviation ( $m \pm S D$ ). A student's t-test for an independent sample was used to check the homogeneity of the two groups (age, weight, and MMS examination). The two-way repeated measures analysis of variance (time* group) was used to compare the "get up and go" test. To compare the Tinetti test, behavioral problems, depression, and miniGDS for the training group before and after the training period, a paired t-test was used. The threshold of significance was set at $p<0.05$.

\section{RESULTS}

The anthropometric characteristics (age, weight, and MMS) did not present significant differences $(p=$ $0.868 ; p=0.841 ; p=0.160$, respectively) between the trained and control groups (Table 1). Furthermore, there were no significant differences $(p=0.183)$ between the two groups regarding mobility ("get up and go" test). Therefore, the two groups were equivalent before training with regards to anthropometry (age and weight), mental capacity (MMS), and physical condition ("get up and go").

Table 1: Anthropometric Characteristics for the Trained and Control Groups

\begin{tabular}{|c|c|c|}
\hline & $\begin{array}{c}\text { Control group } \\
\mathbf{n = 2 0}\end{array}$ & $\begin{array}{c}\text { Trained group } \\
\mathbf{n = 2 0}\end{array}$ \\
\hline \hline Age (year) & $80.7 \pm 7.8$ & $80.2 \pm 9.2$ \\
\hline Weight $(\mathrm{kg})$ & $66.1 \pm 13.7$ & $65.2 \pm 14.6$ \\
\hline Mini Mental State & $18.9 \pm 6.3$ & $15.8 \pm 4.4$ \\
\hline
\end{tabular}

The values are the average $\pm S D ; n$ : number of subjects.

\subsection{Balance Tests}

\subsubsection{Get Up and Go Test and Tinetti Test (Tables 2 and 3)}

Only the "get up and go" test was measured before and after eight weeks of training (Table 2). For both 
groups, there was a significant difference after the eight-week period: a significant decrease $(p<0.05)$ in the completion time of the circuit for the trained group and a significant increase $(p<0.05)$ for the control group.

Table 2: Comparison between the Average Time (Seconds) Spent Completing the "Get Up and Go" Test before (T1) and after the Eight-Week Training Period (T2) for the Training and Control Groups

\begin{tabular}{|c|c|c|}
\hline & T1 & T2 \\
\hline \hline Control group & $19.5 \pm 6.1^{*}$ & $23.1 \pm 8.1$ \\
\hline Trained group & $25.1 \pm 2.9$ & $19.6 \pm 7.1 \S$ \\
\hline
\end{tabular}

The values are the average $\pm S D$; ${ }^{*}$ significant intra-group difference $(p<0,05)$; $\S$ significant inter-group $(p<0,05)$.

Table 3: Comparison between the Average Score on the Tinetti Test before (T1) and after the Eight-Week Training Period (T2) for the Training Group

\begin{tabular}{|c|c|c|}
\hline & T1 & T2 \\
\hline \hline Trained group & $19.5 \pm 4.2^{*}$ & $20.1 \pm 4.1$ \\
\hline
\end{tabular}

The values are the average $\pm S D$; ${ }^{*}$ significant intra-group difference $(p<0,05)$.

Table 3 represents the average scores on the Tinetti test of the trained group. At T2, the values are significantly higher (T1: $19.5 \pm 4.2$; T2: $20.1 \pm 4.1 ; p<$ 0.05).

\subsection{Tests of Behavior and Depression (Table 4)}

\subsubsection{NPI}

As mentioned earlier, the NPI is divided into two parts: the seriousness of the issue and its consequences. Therefore, we separated the results into two parts. A significant difference $(p<0.05)$ between the two tests was observed for the seriousness of the problem (graph 2). A similar result was found for the consequences of the problem (graph 3 ).

Table 4: Comparison between the Average Score on the NPI Test before (T1) and after the Eight-Week Training Period (T2) for the Training Group

\begin{tabular}{|c|c|c|}
\hline & T1 & T2 \\
\hline \hline NPI (seriousness), 36 points & $9.0 \pm 5.5^{*}$ & $7.1 \pm 5.1$ \\
\hline NPI (impact), 60 points & $13.8 \pm 8.7^{*}$ & $11.5 \pm 7.9$ \\
\hline
\end{tabular}

The values are the average $\pm S D$; ${ }^{*}$ significant intra-group difference $(p<0.05)$.

\subsubsection{Mini-GDS}

The mini-GDS was performed on the people reported as depressive in the NPI. Of the 10 people identified, three were not testable because of the advanced stage of the disease. No differences were noticed during the eight-week period for the other seven patients (T1: $2.29 \pm 0.76$; T2: $1.57 \pm 0.53 ; \mathrm{p}>$ 0.05).

\section{DISCUSSION}

The objective of this study was to examine the effects of a short-term physical activity training program, comprising both collective and individual care, for behavior and balance issues in elderly people with Alzheimer's disease. For each test performed (Tinetti and "get up and go" tests), significant improvements were found in the training group (Tables 2 and 3). This difference was only a slight amount but after the eight-week physical program, the staff saw an increase in physical capacity and a behaviour change. In the absence of mental or physical stimulation, the control group declined rapidly because these subjects were very vulnerable and frail. These results are promising and help to validate the role of physical activity on the well-being (physical and psychological) and the physical and psychological capacities of people afflicted with Alzheimer's disease. The results are in agreement with previous studies and justify the development of care support programs involving physical activity for this pathology.

Although the risk of falling is high for Alzheimer's patients, our results indicate that a program of physical activity is an important element to maintain balance functions. Furthermore, the results of the NPI revealed a decrease in the seriousness and consequences of behavioral issues at T2 (Table 4). Therefore, it seems that physical activity not only leads to improvements in physical problems, it also plays a major role in alleviating behavioral issues, confirming the conclusions of several studies on this subject [25-27]. Participation in a program of regular physical exercise can reduce or prevent various functional failures that occur from aging.

There were several expected effects of the physical activity on cognition as well, i.e., improved self confidence, stress and anxiety management, maintenance of focus, attention, memorization, listening training, and instruction comprehension [14]. Regular physical activity can also provide relief to 
depression symptoms and behaviors, as well as improvement to personal control efficiency. Oppert et al. [28] hypothesized that regular physical activity could maintain the cognitive functions of elderly individuals, which could decrease the risk of dementia and Alzheimer's disease. Indeed, Larson et al. [29] have shown a $32 \%$ decrease in the risk of contracting Alzheimer's disease for elderly individuals who train more than three times per week. In a meta-analysis, Etnier et al. [30] found that active people have better cognitive performances than inactive ones. Rejeski et al. [31] purported that there exists a real impact of physical activity on the mental health, quality of life, and well-being of the aging population.

Accordingly, the importance of physical activity on social health can also be hypothesized because of the social link established between people during adapted physical activities and between people and the physical activity teacher. Therefore, physical exercises play an important role in the maintenance of the overall functional state, and they enable the stabilization and improvement of altered cognitive functions.

The limited duration of the training program likely reduces the possible progression level of the physical activity. Despite this limitation, the training program produced encouraging and significant effects for the development and continuation of this type of care. Indeed, the nursing staff in the medical center, who had a deeper look and knowledge of the patients selected for the study and who were able to assess any eventual long-term improvements, were globally surprised by the effects of the program and capacity for development of some of the participants. The staff judged the program as beneficial, not only regarding their long-term personal experiences with the patients, but also when considering the feelings given by the patients themselves.

Consideration of the patient's feelings was relatively complex because of the nature of Alzheimer's disease. The large variations we observed in the behavior over the short period of time can limit the significance and reliability of the responses given to the evaluation and satisfaction questionnaires (mini-GDS), which was done to gather the impressions of the participants on the program. Despite this inherent difficulty, the impressions about the program were positive: the large majority of patients showed their willingness to continue with the program.
The set-up of the program presented stimulating and sometimes difficult challenges. Patients with Alzheimer's disease or a similar pathology are particularly difficult to handle and follow up. For example, failure situations should be avoided, which would have negative impacts on this subset of patients. A progressive program should be established to allow patients to engage in a positive dynamic $[25,26,27]$. Failure situations often cause the patient to discontinue the program. Therefore, close attention and precise knowledge of the capacities of each patient is necessary to develop realistic training and to reach fixed goals.

\section{CONCLUSION}

This preliminary study, which was performed under good experimental conditions, has established the beneficial effects of patients that perform physical exercise. Despite the lack of long-term results, it validates the positive role of physical activity on the behavior and balance regulation of patients affected by Alzheimer's disease.

\section{CLINICAL MESSAGE}

- The objective of this study was to examine the effects of a short-term physical activity training program, for behavior and balance issues in elderly people with Alzheimer's disease.

- The results are in agreement with previous studies and justify the development of care support programs involving physical activity for this pathology.

\section{ETHICS}

The procedures followed were in accordance with the Declaration of Helsinki 1975.

\section{ACKNOWLEDGEMENTS}

We acknowledge the physiotherapists and the participants for their contributions.

\section{CONFLICT OF INTEREST}

The authors declare that there is no conflict of interest.

\section{FUNDING SUPPORT}

This research didn't receive any funding support. 


\section{REFERENCES}

[1] Brookmeyer R, Johnson E, Ziegler-Graham K, Arrighi HM. Forecasting the global burden of Alzheimer's disease. Alzheimers Dement 2007; 3: 186-91.

http://dx.doi.org/10.1016/j.jalz.2007.04.381

[2] Ownby RL, Crocco E, Acevedo A, John V, Loewenstein D. Depression and risk for Alzheimer diseases: systematic review, meta-analysis, and metaregression analysis. Arch Gen Psychiatry 2006; 63: 530-38.

http://dx.doi.org/10.1001/archpsyc.63.5.530

[3] Koss E, Weiner M, Ernesto C, Cohen-Mansfield J, Ferris SH, Grundman $\mathrm{M}$, et al. Assessing patterns of agitation in Alzheimer's disease patients with the cohen-mansfield agitation inventory. The Alzheimer's disease cooperative study. Alzheimer Dis Assoc Disord 1997; 11(Suppl 2): S4550. http://dx.doi.org/10.1097/00002093-199700112-00007

[4] Pariel-Madjlessi S, Pouillon M, Robcis I, Sebban C, Frémont P, Belmin J. Depression: an underrated consequence of stroke in elderly. Psychol Neuropsychiatr Vieil 2005; 3: 7-16.

[5] Bakchine S. Troubles comportementaux dans les démences de type Alzheimer. In: Habib M, Joanette M, Puel M, editors. Démence et syndromes démentiels. Approche neuropsychologique. Paris: Masson 1991; pp. 213-22.

[6] Beauchet O, Allali G, Berrut G, Hommet C, Dubost V, Assal F. Gait analysis in demented subjects: interests and perspectives. Neuropsychiatric Disability Treatment 2008; 4: 155-60.

http://dx.doi.org/10.2147/NDT.S2070

[7] Allan LM, Ballard CG, Rowan EN, Kenny RA. Incidence and prediction of falls in dementia: a prospective study in older people. PloS One 2009; 4: 1-8. http://dx.doi.org/10.1371/journal.pone.0005521

[8] Bean JF, Vora A, Frontera WR. Benefits of exercise for community-dwelling older adults. Arch Phys Med Rehabil 2004; 85: S31-S42.

http://dx.doi.org/10.1016/j.apmr.2004.03.010

[9] Ferrucci L, Izmirlian G, Leveille S, Phillips CL, Corti MC, et al. Smoking, physical activity, and active life expectancy. Am J Epidemiol 1999; 149: 645-53.

http://dx.doi.org/10.1093/oxfordjournals.aje.a009865

[10] Wu SC, Leu SY, Li CY. Incidence of and predictors for chronic disability in activities of daily living among older people in Taiwan. J Am Geriatr Soc 1997; 47: 1082-86. http://dx.doi.org/10.1111/j.1532-5415.1999.tb05231.x

[11] Cress E, Buchner D, Prohaska T, Rimmer J, Brown M, et al. Physical activity programs and behavior counseling in older adult populations. Med Sci Sports Exerc 2004; 36: 19972003.

http://dx.doi.org/10.1249/01.MSS.0000145451.08166.97

[12] Rolland $Y$, Abellan van Kan G, Vellas B. Physical activity and Alzheimer's disease: from prevention to therapeutic perspectives. J Am Med Dir Assoc 2008; 9: 390-405. http://dx.doi.org/10.1016/j.jamda.2008.02.007

[13] Ruscheweyh R, Willemer C, Krüger K, Duning T, Warnecke $\mathrm{T}$, Smmer J, et al. Physical activity and memory functions: an interventional study. Neurobial Aging 2011; 32: 1304-19. http://dx.doi.org/10.1016/j.neurobiolaging.2009.08.001

[14] Depiesse F. Vieillissement et activité physique. Elsevier Masson 2009.

[15] Rejeski WK, Mihalko SL. Physical activity and quality of life in older adults. J Ferontol A Biol Sci Med 2001; 56: 23-25. http://dx.doi.org/10.1093/gerona/56.suppl 2.23
[16] Mauvieux B, Davenne D, Gruau S, Sesboüé B, Denise P. Effet de l'entraînement physique et sportif sur le rythme circadien de la température et le rythme veille-sommeil chez la personne âgée. Science et sports 2002; 18: 93-103. http://dx.doi.org/10.1016/S0765-1597(02)00047-3

[17] Albinet C, Bernard P-L, Palut Y. Contrôle attentionnel de la stabilité posturale chez la personne âgée institutionnalisée: effets d'un programme d'activité physique. Ann Réadap Med Phys 2006; 49: 625-631.

http://dx.doi.org/10.1016/j.annrmp.2006.06.004

[18] Vogel T, Bréchat PH, Lonsdorfer J. Consultation de l'aptitude physique du senior (CAPS) comprenant un programme court de reconditionnement en endurance: le programme d'endurance personnalisé sur cycle (PEP'C). Premiers résultats d'une étude pilote. Science et sports 2007; 24: 21 26. http://dx.doi.org/10.1016/j.scispo.2007.01.011

[19] Hill KD, Logiudice D, Lautenschlager NT, Said CM, Dodd KJ, Suttanon P. Effectiveness of balance training exercise in people with mild to moderate severity Alzheimer's disease: protocol for a randomized trial. BMC Geriatr 2009; 9: 29. http://dx.doi.org/10.1186/1471-2318-9-29

[20] Folstein MF, Folstein SE, McHugh PR. «Mini-mental state». A practical method for grading the cognitive state of patients for the clinician. J Psychiatr Res 1975; 12: 189-98. http://dx.doi.org/10.1016/0022-3956(75)90026-6

[21] Tinetti ME, Baker DI, Claus E, Garrett P, Gottschalk M, Koch $M$, et al. A multifactorial intervention to reduce the risk of falling among elderly people living in the community. $\mathrm{N}$ Engl J Med 1994; 331: 821-827. http://dx.doi.org/10.1056/NEJM199409293311301

[22] Podsiadlo D, Richardson S. The timed "Up \& Go": a test of basic functional mobility for frail elderly persons. J Am Geriatr Soc 1991; 39: 142-8.

http://dx.doi.org/10.1111/j.1532-5415.1991.tb01616.x

[23] Cummings JL, Mega M, Gray K, Rosenberg-Thompson S, Carusi DA, Gornbein J. The Neuropsychiatric Inventory: Comprehensive assessment of psychopathology in dementia. Neurology 1994; 44: 2308-2314.

http://dx.doi.org/10.1212/WNL.44.12.2308

[24] Clément JP, Nassif RF, Leger JM, Marchan F. Mise au point et contribution à la validation d'une version française brève de la Geriatric Depression Scale de Yesavag. L'Encéphale 1997; XXIII: 91-9.

[25] Williams CL, Tappen RM. Effect of exercise on mood in nursing home residents with Alzheimer's disease. Am J Alzheimers Dis Other Demen 2007; 22: 389-97. http://dx.doi.org/10.1177/1533317507305588

[26] Lautenschlager NT, Cox KL, Flocker L, et al. Effects of physical activity on cognitive function in older adults at risk for Alzheimer's disease. JAMA 2008; 300: 1027-37.

http://dx.doi.org/10.1001/jama.300.9.1027

[27] Hernandez SS, Coelho FG, Gobbi S, Stella F. Effects of physical activity on cognitive functions, balance and risk of falls in ederly patients with Alzheimer's dementia. Rev Bras Fisioter 2010; 14: 68-74.

http://dx.doi.org/10.1590/S1413-35552010000100011

[28] Oppert JM, Simon C, Rivière D. Activité physique: arguments scientifiques, pistes pratiques. Collection « Les synthèses du PNNS ». Paris: Ministère de la Santé. 2006; p. 58.

[29] Larson EB, Wang L, Bowen JD, Mc Cormick WC, Teri L, Crane $\mathrm{P}$, et al. Exercise is associated with reduced risk for incident dementia among persons 65 years of age and older. Ann Intern Med 2006; 144: 73-81. http://dx.doi.org/10.7326/0003-4819-144-2-200601170$\underline{00004}$ 
[30] Etnier JL, Nowell PM, Landers DM, Sibley BA. A metaregression to examine the relations ship between aerobic fitness and cognitive performance. Brain Res Rev 2006; 52 : 119-30.

http://dx.doi.org/10.1016/j.brainresrev.2006.01.002
[31] Rejeski WJ, King AC, Katula JA, Kritchevsky S, Miller ME, Walkup MP, et al. Physical activity in prefrail older adults: confidence and satisfaction related to physical function. J Gerontol B Psychol Sci Soc Sci 2008; 63: 19-26.

http://dx.doi.org/10.1093/geronb/63.1.P19

Received on 28-03-2016

Accepted on 13-04-2016

Published on 28-07-2016

DOI: http://dx.doi.org/10.6000/2292-2598.2016.04.02.4

(C) 2016 Claire et al.; Licensee Lifescience Global.

This is an open access article licensed under the terms of the Creative Commons Attribution Non-Commercial License (http://creativecommons.org/licenses/by-nc/3.0/) which permits unrestricted, non-commercial use, distribution and reproduction in any medium, provided the work is properly cited. 